\title{
Adverse effect left congenital diaphragmatic hernia to position and function of the fetal heart
}

\author{
Adhi Pribadi*, Johanes Cornelius Mose
}

\begin{abstract}
Department of Obstetrics \& Gynaecology, Hasan Sadikin General Hospital University of Padjadjaran, Bandung, Indonesia
\end{abstract}

Received: 24 September 2015

Accepted: 30 October 2015

\section{*Correspondence:}

Dr. Adhi Pribadi,

E-mail: priana1001@gmail.com

Copyright: ( ) the author(s), publisher and licensee Medip Academy. This is an open-access article distributed under the terms of the Creative Commons Attribution Non-Commercial License, which permits unrestricted non-commercial use, distribution, and reproduction in any medium, provided the original work is properly cited.

\begin{abstract}
Background: There many heart problems in patients with $\mathrm{CDH}$.

Methods: Between January 2012 and July 2015, three pregnancies (1:2153) performed ultrasound examination to investigate suspected CDH. All symptoms displayed descriptively in table.

Results: In prenatal life, ultrasonography has a high sensitivity for detection of congenital diaphragmatic hernia. The definite ultrasonographic diagnosis of fetal congenital diaphragmatic hernia lies on the visualization of abdominal organs in the chest. The ultrasonographic hallmark of this condition is a fluid-filled mass in same level with fetal heart. Ultrasonographic features indicative of congenital diaphragmatic hernia include polyhydramnios; an absent or intraabdominal stomach bubble, mediastinal-cardiac shift away from the side of the herniation and a small fetal abdominal circumference or growth retarded. The effect of stomach pressure results $100 \%$ the position of the heart and affect the effectiveness of the heart such as pressure on the heart resulting tamponade effect.

Conclusions: Cardiac changes due to the insistence by $\mathrm{CDH}$ can lead to changes position, anatomical and cardiac function.
\end{abstract}

Keywords: CDH, Complication, Fetal heart

\section{INTRODUCTION}

Diaphragmatic hernia was inclusion of abdominal organs through a defect in the diaphragm into the chest cavity. Congenital diaphragmatic hernia $(\mathrm{CDH})$ was the most common cause of diaphragmatic hernia although still encountered abnormality obtained. In general, there were three basic common types congenital diaphragmatic hernia: Bochdalek hernia (posterolateral) accounting for more than $95 \%$ of cases most arise in the area posterior left thoracic cavity, Morgagni hernia (parasternal or anterior) account for $9 \%$ to $12 \%$ of diaphragmatic defects in infancy (right-side in $90 \%$ cases) and the widening of the esophageal hiatus (hiatal hernia). ${ }^{1-3}$

Bochdalek Hernia occurs due to failure of the membrane closure left pleuroperitoneal, while the Morgagni hernia arises posterior processus xiphoideus, due to the failure of the unification of rib and sternal muscle (left or right parasternal). When the defect is located on the left side, the thorax may contain small and large bowel, the spleen, the stomach, the left lobe of the liver and, occasionally, the kidney. Right-sided $\mathrm{CDH}$ usually contain part of the right lobe of the liver and sometimes the bowel and/or the kidney. ${ }^{4,5}$

Case of $\mathrm{CDH}$ if arise in the left thorax cavity will lead to compress of fetal heart so that when arising since early pregnancy, directly will potentially lead to anatomical abnormalities. In the event of anatomical abnormalities, cardiac function will disturb so the pumping of the blood throughout the body of the fetus. ${ }^{6}$

\section{METHODS}

This research was conducted at the General Hospital Dr. Hasan Sadikin (RSHS) descriptively. Between January 
2012 and July 2015 obtained 3 pregnancies were diagnosed $\mathrm{CDH}$ from 6,460 live deliveries. Three pregnancies with result ultrasound examination suspected Congenital Diaphragmatic Hernia $(\mathrm{CDH})$ referred by satelite hospital to the Division of Maternal Fetal Medicine Department Obstetrics \& Gynecologi, Hasan Sadikin General Hospital, University of Padjadjaran, Indonesia. All cases performed ultrasound examination to investigate suspected $\mathrm{CDH}$. All cases established $\mathrm{CDH}$ and symptoms displayed descriptively in table.

\section{RESULTS}

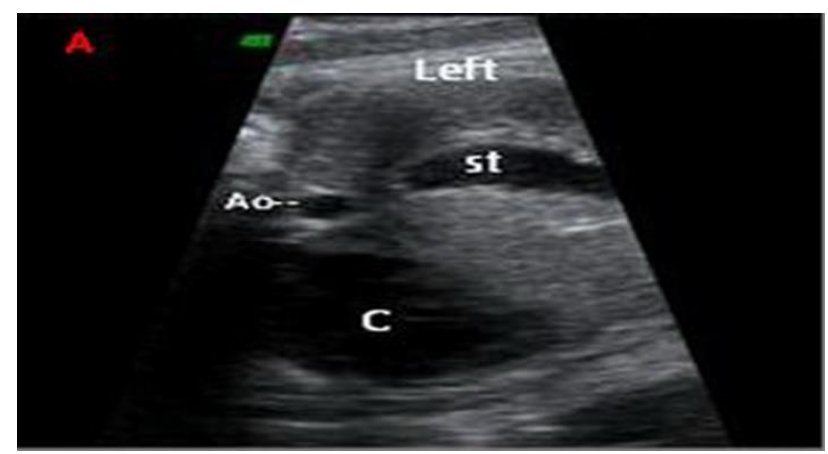

Figure 1(A): Thoracal transverse section shows the position of the heart $(\mathrm{C})$ same level opposite side with stomach (st) location.

\section{AO: Aorta}

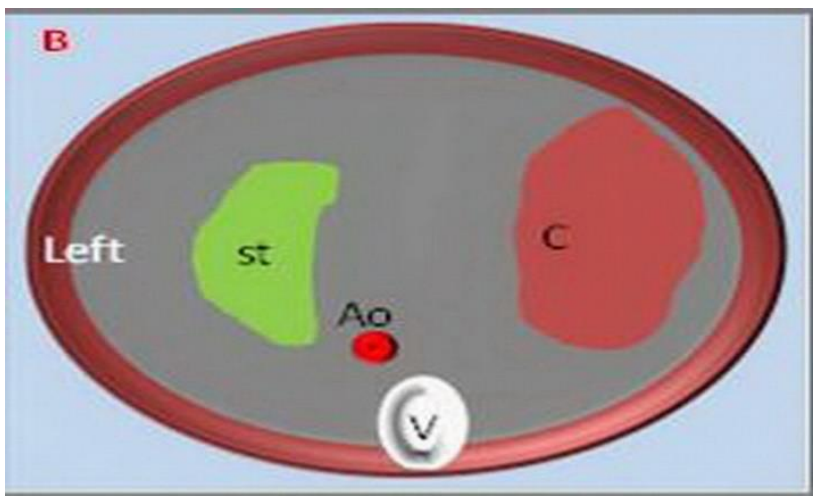

Figure 1(B): Ilustration fig 1A. The position of the heart (c) and stomach (st) are in the opposite side, but still at the same level. Heart pushed to the right side possibility of urging the stomach and left lung. St: Stomach, C: Cor, AO: Aorta, V: Spine

The first case (Figure1A,1B) was gravid 34-35 weeks, with an ultrasound appearance pointed that the location fetal stomach opposite side with the location of fetal heart but still in same level and the axis direction still to the left (Dextroposition). Other heart abnormalities was the presence of the insistence of the left ventricle so that the ventricles seen an equal. Location of the heart in the right thoracic cavity because of pressure from the stomach enters the left thoracic cavity. Fetal growth still undisturbed, with active motion and there were no other congenital abnormalities. Diagnosis clinic for the first case was $\mathrm{CDH}$ Bochdalek with heart insistence to the right and left heart ventricle became mild hypoplasia maybe caused by insistency. After established diagnosis the patient was returned to the satelite hospital and after delivery the fetus immediately performed surgery to repair the diaphragm by pediatric surgeon.

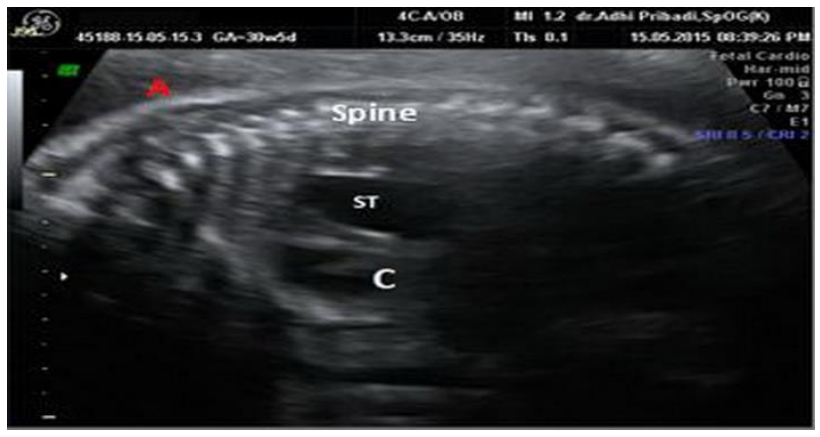

Figure 2(A): Thoracal sagittal section. Stomach (st) position posterior from heart (c) in front of the spine (posterolateral).

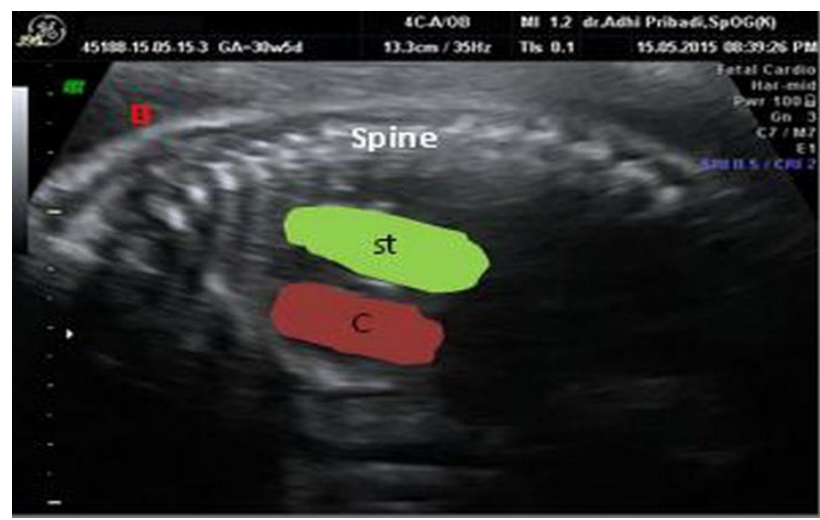

Figure 2(B): Sagittal section. Shows where the heart (c) was pushed forward by the stomach (st) which fills St: Stomach, C: Cor posterolateral region.

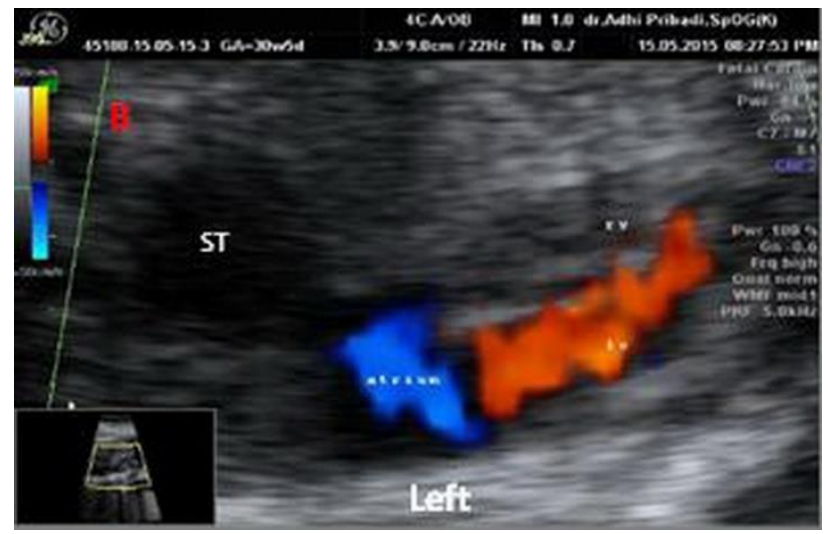

Figure 2(C): Heart level transverse section. Use of doppler showing severe hypoplastic right heart, so that part of the heart which looks only a single atrium, left ventricle and the rest of the right ventricle. c: cor, st: stomach, vu: vesica urinaria. 
The second case (Figure 2A,2B,2C) has a different ultrasound appearance with the first case; the second case was referred with complaint intrauterine growth retardation (IUGR). Ultrasound examination showed the heart was still in the left thoracic cavity with heavy insistence anteriorly so as to achieve the anterior wall. On the back of the heart, there was a fluid filled mass as fetal stomach pressing heart towards anteriorly. Part of the right ventricle of the heart of great urgency resulting in severe narrowing of the right ventricle became hypoplastic right ventricle, with tricuspid valve stenosis. Left ventricle dilation with abnormalities of the mitral valve regurgitation. Partially of the blood flow directly from the vena cava enters the right atrium section, in addition septum primum and secundum cannot be identified (uniatrial). Cardiothoracic ratio was under limit $(16 \%)$ impression heart tamponade. Polyhidramnios was other patologi condition. Fetal has severe growth retarded and death in utero (IUFD) 2 days upon termination preparations were underway. Viewing location was in left posterolateral thorax show case was $\mathrm{CDH}$ Bochdalek or left diaphragm hernia.

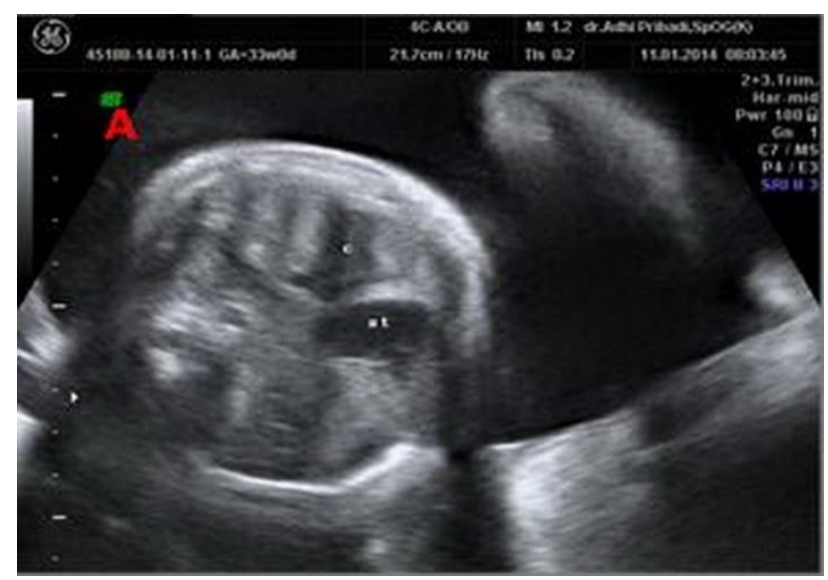

Figure 3(A): Thoracal transverse section. Stomach (st) appear side by side with the heart (c), in this case the location of the stomach was located in the anterior thoracic cavity.

c:heart st:stomach

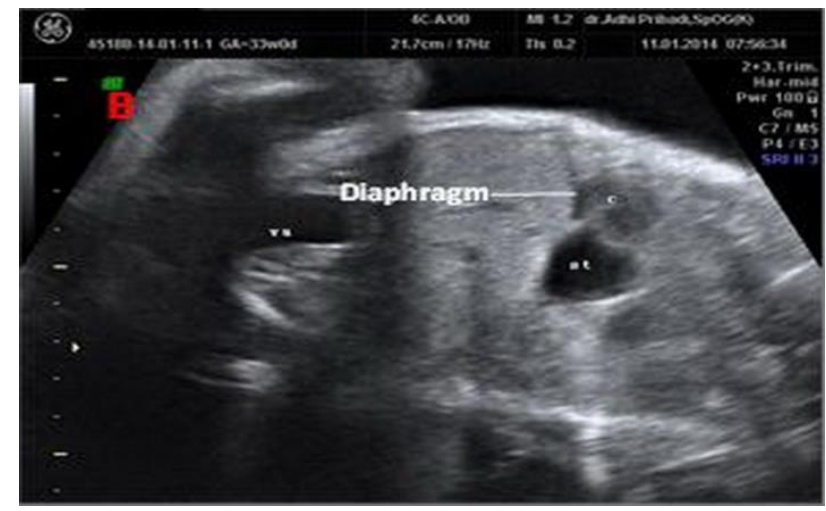

Figure 3(B): Longitudinal section. Shows where the heart (c) was pushed forward by the stomach (st) part.

st: stomach, C: cor, rv: rigth ventricle, lv: left ventricle

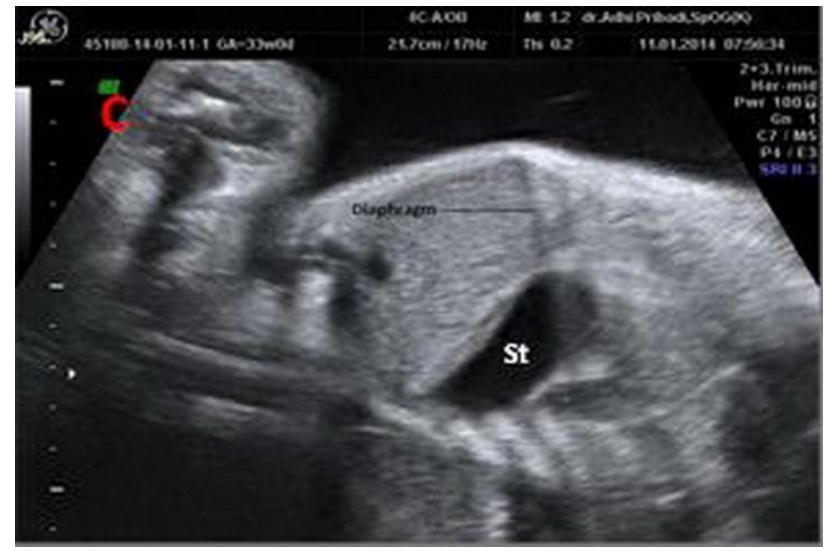

Figure 3(C): Coronal section. Stomach seemed to penetrate the diaphragm to enter the thorax. St:stomach

The third case (Figure 3A,3B,3C) was referred with suspicion of cystic mass beside of the heart. Ultrasound examination shows a picture of the heart was still in the left thoracic cavity but pushed to the left with cardiothoracic ratio below normal limit. Anatomy of the heart there was no abnormality; likewise there was no interference with the frequency. Cystic mass located anterior thorax cavity in the left parasternal area. Third picture on coronal section show stomach into the left thoracic cavity. After delivery, the baby carried by a pediatric surgeon to repair surgery and survived. Saw the position of the stomach was in the anterior thoracic cavity posterior of the sternum or parasternal, this case was the type of Morgagni CDH.

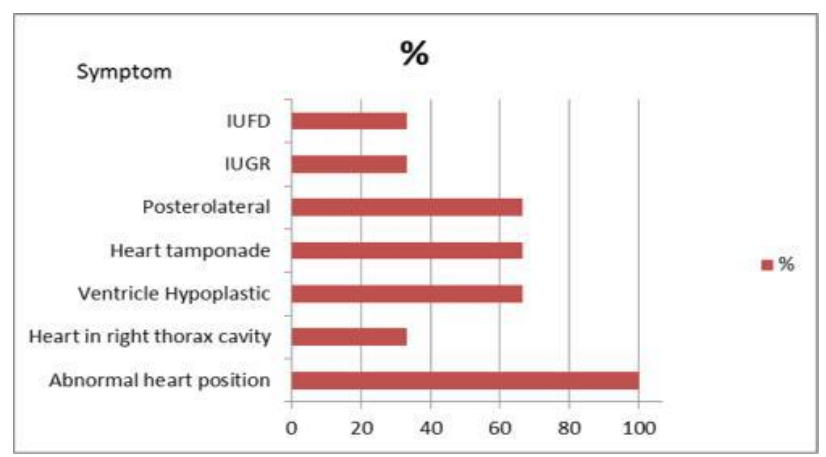

Figure 4: Symptom and complication of all cases.

\section{DISCUSSION}

The prevalence of $\mathrm{CDH}$ ranges between 1:2000 and 1:4000 live births. ${ }^{7}$ This research found prevalence of CDH similar (1:2153) with other literature or research. Antenatal diagnosis can be performed with ultrasound. Routine ultrasound scans of pregnant women in the second trimester have increased the antenatal detection rate of $\mathrm{CDH}$. Diagnosis hernia Bochdalek can be done during antenatal, based on the ultrasound picture of abdominal organs entering left thoracic cavity, there is stomach or others organs into the chest cavity, and the 
shifting lies the heart of its normal position caused by the pressure. ${ }^{1,2,7}$ Location of the heart can be shifted to the right or insistence towards the front approaching the anterior thoracic wall.). ${ }^{6,7} \mathrm{CDH}$ suspicion can be enforced were no stomach appearance in the abdominal cavity, mediastinal shift, polyhydramnios happen to some severe cases ( $80 \%$ of cases Bochdalek hernia accompanied by polyhydramnios) and rarely there may be fetal hydrops. ${ }^{1,2}$

Typical findings are the presence of the stomach or loops of bowel within the thoracic cavity-ideally level with the 'four-chamber' view of the fetal heart, along with mediastinal shift away from the side of the lesion. The diagnosis can be missed if the stomach is not in the thorax, right-sided defects are also more difficult to diagnose. ${ }^{7}$ This can be seen in all cases that the stomach looks at levels as high as 'four-chamber' view.

Management may include medical therapy, supportive, and corrective surgery to restore the abdominal organs in the chest cavity to the abdomen. Definite etiology of $\mathrm{CDH}$ was still unclear just $2 \%$ were related to a family illness, and about $15 \%$ of cases associated with chromosomal abnormalities. At this time it is known that $\mathrm{CDH}$ associated with the location of genes that play a role in the development of the diaphragm at chromosomal 15q26. Chromosomal 13, 18, 21 abnormalities often accompanied by $\mathrm{CDH}^{7}$

The study population showed $30 \%$ of fetuses with diaphragmatic hernia died before birth and associated with chromosomal abnormalities or other congenital lethal like failure heart function and retarded fetal growth.

Bochdalek hernia, also known as posterolateral diaphragmatic hernia, the intestinal herniation and sometimes the spleen and liver through a defect in the posterolateral region of the diaphragm. ${ }^{1}$ Pathophysiology At the age of 8 weeks of pregnancy there is no emphasis on developing diaphragms, pressure can come from the chest cavity and abdominal cavity. Inside the chest cavity, the lungs have not developed; while in the abdominal cavity gut still take place outside of the abdomen that is at the umbilicus. ${ }^{8}$

The first mechanical pressure received by the diaphragm is when the bowel back from the umbilicus to the intraabdominal at week 10. At that time, part of the diaphragm has occupied a normal place to receive emphasis as a consequence of the development of organs. Impaired formation of the diaphragm can be partially forming a diaphragm failure, disruption of fusion between elements pleuroperitonei or disorders of muscle formation, which may cause the diaphragm becomes thin and lead occur eventrasi, caused the widening of the esophageal hiatus and the weakness of the ligament phrenoesophageal still unclear. $^{8}$

Approximately $90 \% \mathrm{CDH}$ was on the left side of the layout posterolateral. ${ }^{1}$ Gradation level of adverse effects of left $\mathrm{CDH}$ depending on other conditions, such as pulmonary hypoplasia, pulmonary hypertension, as well as the insistence on the location of the heart. ${ }^{1,9}$ The effect of stomach pressure results in a change in the position of the heart and affect the effectiveness of the heart such as changes in the location of major blood vessels and the pressure on the heart resulting in tamponade effect. ${ }^{10,11}$ Heavy tamponade effect in long term resulting incomplete development of the chambers of the heart (4 chamber) that also affect decreased effectiveness of pumping power of the heart (case $1^{\text {st }}, 2^{\text {nd }}$ ). In long term will result to fall fetal heart decompensation.

\section{CONCLUSIONS}

Cardiac changes due to the insistence by $\mathrm{CDH}$ can lead to changes position, anatomical and cardiac function.

\section{Funding: No funding sources \\ Conflict of interest: None declared}

Ethical approval: The study was approved by the Institutional Ethics Committee

\section{REFERENCES}

1. Juan A Tovar. Congenital Diaphragmatic Hernia. Tovar Orphanet Journal of Rare Diseases. 2012;7:115 .

2. Taylor GA, Atalabi OM, Estroff JA. Imaging of congenital diaphragmatic hernias. Pediatr Radiol. 2009;39:1-16.

3. Stolar CJH. Congenital diaphragmatic hernia. In: Oldham KT, Colombani PM, Foglia RP (eds) Surgery of infants and children: scientific principles and practice. Philadelphia: Lippincott-Raven; 1997: 88395.

4. Clark RH, Hardin WD Jr, Hirschl RB, Jaksic T, Lally $\mathrm{KP}$, Langham MR Jr, et al. Current surgical management of congenital diaphragmatic hernia: a report from the Congenital Diaphragmatic Hernia Study Group. J Pediatr Surg. 1998;33:1004-9.

5. Seaward GR. The fetal chest. In: Rumack CM, Wilson SR, Charboneau JW (eds) Diagnostic ultrasound, 3rd edn 2005. Elsevier Mosby, St. Louis; 2005: 1303-1321.

6. Siebert JR, Haas JE, Beckwith JB. Left ventricular hypoplasia in congenital diaphragmatic hernia. J Pediatr Surg. 1984;19:567-71.

7. King H, Booker PD. Congenital diaphragmatic hernia in the neonate. Continuing Education in Anaesthesia, Critical Care \& Pain. 2005;5:171-4.

8. Clugston RD, Klattig J, Englert C, et al. Teratogeninduced, dietary and genetic models of congenital diaphragmatic hernia share a common mechanism of pathogenesis. Am J Pathol. 2006;169:1541-9.

9. Harrison MR, Jester JA, Ross NA. Correction of congenital diaphragmatic hernia in utero. I. The model: intrathoracic balloon produces fatal pulmonary hypoplasia. Surgery. 1980; 88:174-82.

10. Lin AE, Pober BR, Adatia I. Congenital 
diaphragmatic hernia and associated cardiovascular malformations: type, frequency, and impact on management. Am J Med Genet C Semin Med Genet. 2007;145C:201-16.

11. Migliazza L, Otten C, Xia H, Rodriguez JI, DiezPardo JA, Tovar JA. Cardiovascular malformations in congenital diaphragmatic hernia: human and experimental studies. J Pediatr Surg. 1999;34:1352-8.

Cite this article as: Pribadi A, Mose JC. Adverse effect left congenital diaphragmatic hernia to position and function of the fetal heart. Int J Reprod Contracept Obstet Gynecol 2015;4:1863-7. 